\title{
O Projeto COMO UMA Metáfora Biológica DOS PROCESSOS PSÍQUICOS ${ }^{1}$
}

\author{
Leopoldo Fulgencio ${ }^{2}$ \\ Programa de Estudos Pós-Graduados em Psicologia Clínica - \\ Pontifícia Universidade Católica de São Paulo
}

\begin{abstract}
Este artigo pretende mostrar que o Projeto de uma Psicologia, escrito por Freud em 1895, é uma metáfora. Corresponde à sua primeira tentativa para produzir uma teoria geral sobre o psiquismo, na qual encontramos uma metapsicologia formulada em termos biológicos. Defende-se que esta metapsicologia, por sua vez, não é proposta como uma neuropsicologia, mas como um conjunto de construções auxiliares, especulativas, cujo valor é apenas heurístico, aplicáveis aos problemas de natureza psíquica, relacionados com o método de tratamento que Freud estava desenvolvendo.
\end{abstract}

Descritores: Metapsicologia. Metáfora. Neuropsicologia.

$\mathrm{E}_{\mathrm{p}}^{\mathrm{n}}$ m 1895, aproximadamente treze anos depois de ter abandonado suas pesquisas histológicas e neurológicas, iniciadas no laboratório de fisio-

1 Este artigo corresponde a um dos capítulos de minha tese de doutorado, intitulada O método especulativo em Freud, PUC-SP, 2001, que foi revisto e modificado para esta publicação. Este trabalho se insere na linha de pesquisa do Grupo de Pesquisa em Filosofia e Práticas Psicoterápicas da PUC-SP (www.cle.unicamp.br/grupofpp). Agradeço ao $\mathrm{CNPq}$ e à FAPESP pelo auxílio dado para o desenvolvimento dessa pesquisa.

2 Doutor em Psicologia Clínica pela Pontifícia Universidade Católica de São Paulo, Membro do GFPP e do Departamento de Psicanálise do Instituto Sedes Sapientiae, Professor Titular da Universidade Paulista (UNIP). Endereço para correspondência: Rua Ministro Godoi, 679, ap. 53, Perdizes, São Paulo - SP. CEP 05015-000. Fone: (011) 3862 6919. Endereço eletrônico: ful@that.com.br 
logia de Brücke, 3 caminhando, cada vez mais, em direção à prática e à elaboração do tratamento das psiconeuroses, Freud se vê próximo da possibilidade de elaborar uma teoria geral sobre o funcionamento psíquico. Nesse momento, ele via aberta uma perspectiva de formulação efetiva de uma psicologia geral: "[a psicologia] foi sempre minha meta distante, a acenar-me, e agora, desde que me deparei com o problema das neuroses, aproximourse muito mais" (Freud \& Fliess, 1986, [25/05/1895], p. 130). Seu objetivo era construir uma psicologia como ciência natural, que pudesse servir tanto ao entendimento das psicopatologias quanto da vida psíquica normal, ainda que isso lhe parecesse muito difícil de ser realizado:

Estou atormentado por dois objetivos: examinar que forma irá assumir a teoria do funcionamento mental, se introduzirmos considerações quantitativas, uma espécie de economia das forças nervosas, e, em segundo lugar, extrair da psicopatologia um ganho para a psicologia normal. Na verdade, é impossível ter uma concepção geral satisfatória dos distúrbios neuropsicóticos se não se puder vinculá-la com pressupostos claros sobre os processos mentais normais. (Freud \& Fliess, 1986, [25/05/1895], p. 130)

No início de seu Projeto de uma Psicologia, ${ }^{4}$ ele confirma a intenção de suas elaborações: "O propósito [é] fornecer uma psicologia científiconaturalista, ou seja, apresentar processos psíquicos como estados quantitativamente determinados de partes materiais capazes de serem especificadas e, com isso, torná-los intuitivos e livres de contradição" (Freud, 1895/1995, p. 9).

O que Freud tem em mãos, em primeiro lugar, são os dados observados no tratamento de seus pacientes neuróticos. São eles o seu campo empírico. O princípio básico que ele formula para o funcionamento psíquico, segundo o qual se supõe existirem quantidades de excitação móveis, é pen-

3 Freud, a conselho do próprio Brücke, abandona o Laboratório para dedicar-se à carreira médica, em 1882 (Freud, 1925, p. 10).

4 Doravante, esta obra será nomeada, apenas, Projeto.

5 No sentido em que se possa ter uma experiência sensível desses processos, ainda que de forma não direta (logo, de forma inadequada) e conseguida por meio de analogias (Nota minha). 
sado em função dos fenômenos clínicos observados: "[essa concepção quantitativa] decorreu de observação clínico-patológica, em que se tratou em especial da representação superintensa, como no caso da histeria e da compulsão, nos quais, como se mostrará, o caráter quantitativo se sobressai de forma mais pura do que em [processos] normais" (Freud, 1895/1995, p. 9).

Trata-se, para ele, de uma tentativa de "generalizar aquele conhecimento" (Freud, 1895/1995, p. 9). Quando Freud traça o esboço dessa teoria psicológica geral, descrita em termos neurobiológicos, ele parte de dois princípios especulativos, considerando-os necessários para uma psicologia enquanto ciência natural. Em primeiro lugar, o pressuposto de que o psiquismo humano deve ser tomado como um objeto natural, um aparelho, e, em segundo, de que os movimentos próprios a esse aparelho podem ser compreendidos em termos de quanta de excitação móveis, ou seja, as representações hiperintensas e os sintomas associados a elas nas neuroses podem ser compreendidos em termos de quantidades de excitação (energias) que se deslocam.

Esse quantum de excitação móvel já havia sido postulado por Freud, em 1894, como uma construção auxiliar de valor apenas heurístico:

[...] exporei em poucas palavras a representação auxiliar da qual me servi nesta exposição das neuroses de defesa. É a seguinte: nas funções psíquicas, cabe distinguir algo (montante de afeto, soma de excitação) que tem todas as propriedades de uma quantidade - ainda que não haja meio algum de medi-la -; algo que é suscetível de aumento, diminuição, deslocamento e descarga, e que se difunde pelas marcas mnêmicas das representações, como faria uma carga elétrica pela superfície dos corpos. [...] Ela é justificável, provisoriamente, porque ela é útil para reagrupar e explicar os diversos estados psíquicos. (1894, pp. 60-61)

A passagem dos dados empíricos para um modelo geral do funcionamento mental, no Projeto, é feita com o auxílio de representações auxiliares de natureza especulativa, tais como a noção de energia nervosa, quantum de afeto, neurônios diferenciados, caminhos facilitados, aparelho psíquico. Ele mesmo alude a esse seu fantasiar teórico, numa carta a Fliess de 25/03/1895: 
Nestas últimas semanas, tenho dedicado cada minuto livre a esse trabalho; tenho gasto horas noturnas, das onze às duas, com fantasias, interpretações e palpites $\mathrm{e}$, invariavelmente, só me detenho quando, em algum momento, esbarro num absurdo ou sinto-me real e seriamente esgotado pelo trabalho, de modo que nenhum interesse me resta por minhas atividades médicas diárias. (p. 130. Os itálicos são meus)

Quais são os problemas que Freud procura solucionar com suas teorias? Não são os da neurobiologia, ${ }^{6}$ mas os da psicologia clínica, ou seja, a explicação das relações que justificam e revelam os mecanismos de produção dos sintomas, nas patologias, e dos atos psíquicos, nas pessoas normais. Freud, bem formado que foi no laboratório de Brücke, sabe que a pesquisa das estruturas neurológicas necessitam de um campo de apoio experimental diferente do que ele tem em mãos. Basta ver os seus trabalhos sobre neurologia para reconhecer o fundo experimental que ele utilizava para formular suas hipóteses (Freud, 1897).

Ao tentar tratar de seus pacientes neuróticos, Freud observa que, se ficamos apenas no nível da consciência, não é possível encontrar uma explicação, sem lacunas, para os sintomas psicopatológicos, sendo necessário completar essas lacunas supondo outros processos e determinantes. Numa passagem de seu texto sobre o inconsciente, de 1915, Freud diz claramente qual é a sua perspectiva de pesquisa, que considero já estar presente em 1895:

6 Como comenta Etcheverry, numa nota relativa ao Projeto de Freud: "O termo 'neurônio' foi cunhado em 1891 por W. Waldeyer para designar a unidade fundamental do sistema nervoso. As investigações histológicas de Freud o tinham conduzido à mesma descoberta. Ver, em particular, 'A estrutura dos elementos do sistema nervoso’ (Freud, 1884)” (Etcheverry, 1976 p. 339). Ernest Jones também comenta que, nesse trabalho, "Freud sintetizou suas investigações sobre a estrutura do sistema nervoso ['Sobre a origem das raízes posteriores na moela épinère do Ammocoetes' (1887); 'Observações sobre a configuração e a estrutura fina dos órgãos lobulares, descritos como sendo os testículos da enguia' (1887); 'Sobre os gânglios espinhais da moela espinhal do Petromyzon' (1878); 'Notícia sobre um método para a preparação anatômica do sistema nervoso' (1879); 'Sobre a estrutura das fibras nervosas e células nervosas no caranguejo' (1882)] e abriu o caminho para a teoria do neurônio, que seria formulada por Waldeyer, em 1891" (Jones, 1953, v. 1, pp. 53-56). 
[...] os dados da consciência são, num alto grau, lacunares; tanto nas pessoas sãs como nos doentes, produzem-se freqüentemente atos psíquicos que, para sua exp licação, pressupõem outros atos que, de qualquer maneira, a consciência não atesta. Tais atos não são somente os atos falhos e os sonhos nas pessoas sãs, [mas] tudo o que se chama de sintomas psíquicos e fenômenos de obrigação [obsessivos] nos doentes. (Freud, 1915b, p. 166)

Num certo sentido, poder-se-ia tentar preencher essas lacunas buscando aquilo que a fisiologia poderia fornecer ao psicólogo. Essa perspectiva de pesquisa estaria, inclusive, de acordo com uma posição expressa por Ernst Mach (1838-1916) que, ao referir-se ao nosso Eu (como expressão de nossa vida psíquica), diz não ser necessário supor, para conhecermos nosso psiquismo, "alguma coisa de não conhecida e incognoscível que em nada nos ajudaria para uma compreensão melhor. Atrás do eu há sempre uma coisa quase inexplorada: o nosso corpo" (Mach, 1905/1922, p. 24). No entanto, não é esta a opção de Freud, ele não se colocará como fisiólogo, anatomista ou neurólogo. Declarações bem posteriores a esse momento do Projeto mostram em que lugar ele se posicionará, seja colocando a psicanálise num campo diferente da filosofia ou da fisiologia ${ }^{7}$ seja marcando claramente que não há correspondência entre os modelos metapsicológicos e a anatomia cerebral (Freud, 1925, p. 32). Freud manter-se-á no campo da psicologia, evitando, no entanto, reduzir a psicologia à consciência. Ele avalia que não será noutras disciplinas que as explicações sobre os fenômenos psíquicos serão encontradas e seu objetivo alcançado, ou seja, não será na filosofia, na neurofisiologia ou, ainda, numa psicologia da consciência, mas tão-somente numa psicologia do inconsciente.

Estamos no direito de responder que a assimilação convencional do psiquismo ao consciente é absolutamente inadequada. Ela dilacera as continuidades psíquicas, precipita-nos nas dificuldades insolúveis do paralelismo psicofísico, fica exposta à

7 Note-se, por exemplo, o comentário de Freud: "O que me parece mais sujeito à reflexão é que a [Sabina] Spielrein quer subordinar o material psicológico a pontos de vista biológicos; esta dependência deve ser rejeitada tanto quanto a dependência filosófica, fisiológica ou da anatomia do cérebro" (Freud \& Jung, 1992 [30/11/1911], p. 589). 
reprovação de superestimar, sem fundamentação visível, o papel da consciência e nos compele a abandonar prematuramente o âmbito da indagação psicológica, sem poder nos trazer ressarcimento vindo de outros domínios. (Freud, 1915b, p. 167. Os itálicos são meus)

Freud diz a Fliess, referindo-se à sua procura de uma psicologia geral, que ele deseja obter explicações que vão além do que a psicologia descritiva podia oferecer; ele refere-se à sua procura de soluções metapsíquicas para os problemas da psicologia ( Freud \& Fliess, 1986, [10/03/1898], p. 302).

Algumas das afirmações de Freud, acima citadas, são bem posteriores ao ano de redação do Projeto. Em 1895, Freud ainda parece sobrepor a biologia à psicologia, considerando frutífero modelar sua teoria geral das ne uroses em termos do conceito de quantidade (energética) como princípio fundamental da atividade neuronal, esperançoso de que esse princípio pudesse "ser muito esclarecedor, na medida em que parecia abranger a função [psíquica] em sua totalidade" (Freud, 1895/1995, p. 10). A esse pressuposto de quanta de energia (excitação), presentes nos neurônios, Freud aplica uma formulação advinda da termodinâmica - na qual sua segunda lei diz que no interior de um sistema fechado os diferentes níveis energéticos tendem para a igualdade, de maneira tal que o estado ideal final é o equilíbrio - e da física, com sua lei da inércia, explicitando, então, qual é o princípio fundamental da atividade neuronal: "[o] n[eurônio] aspira libertar-se de Q [quantidade]" (Freud, 1895/1995, p. 10). Assim, a primeira psicologia geral de Freud é um modelo teórico que utiliza um vocabulário relativo a termos da física e da biologia, para a qual os neurônios são uma referência mais ou menos empírica.

8 Digo "mais ou menos" porque os neurônios, em geral, eram uma evidência empírica dada pela neurobiologia; no entanto, a hipótese de que existiriam neurônios de diversos tipos é já uma especulação de Freud. Para ele, a simples possibilidade lógica de que eles possam existir, mesmo sem índices empíricos, serve como justificativa para a sua suposição: "De onde mais se deve retirar um fundamento para essa divisão em classes [de neurônios]? Se possível, do desenvolvimento biológico do sistema nervoso, que é, para o investigador da natureza, como todas as outras coisas, algo que se formou gradualmente" (Freud, 1895/1995, p. 16). 
Como princípio-guia dessa tentativa de 1895, Freud coloca sua premissa fundamental: a consideração de que é necessário conceber um inconsciente psíquico, mas descrito em termos biológicos. Diz Freud:

Imediatamente esclarecemos um pressuposto que nos guiou até aqui. Temos tratado os processos psíquicos como algo que poderia prescindir desse conhecimento dado pela consciência, que existe independente de uma tal consciência. Se não nos deixarmos desconcentrar por tal fato, segue-se desse pressuposto que a consciência não proporciona nem conhecimento completo, nem seguro, dos processos neuronais; cabe considerá-los, em primeiro lugar e em toda extensão, como inconscientes e cabe inferi-los com as outras coisas naturais. (Freud, 1895/1995, p. 22)

Outros comentadores da obra de Freud, e especialmente do Projeto, também já reconheceram essa hipótese como um fator diferenciador das propostas freudianas das outras psicologias. Pribram e Gill, por exemplo, comentam que a grande originalidade do Projeto foi o enfoque dedicado aos mecanismos e processos psíquicos inconscientes:

O que há de único, então, no Projeto ? O traço característico do desvio empreendido por Freud está em sua revelação da importância e do significado do comportamento inconsciente determinado como indicador de um processo cientificamente acessível, ao passo que os outros [autores que propuseram algo semelhante em sua época, por exemplo, Exner em 1894] tinham se preocupado meramente com o óbvio, isto é, a consciência. (Pribram \& Gill, 1976, pp. 13-14)

Freud tinha, no horizonte teórico de sua época, conhecimento de outros cientistas que também propunham a consideração da existência de processos psíquicos inconscientes - tais como, Charcot, Janet, Lipps -, levando a considerar esses processos como um fato observável empiricamente. ${ }^{9}$ Tratava-se, no entanto, de ir além desse conhecimento meramente descritivo do inconsciente, pois tal conhecimento não consegue fornecer a série completa das determinações causais desses fenômenos, deixando lacunas no entendimento, ou seja, era necessário ir além da teoria psicológica (descritiva), o

9 A sugestão hipnótica, por exemplo, comp rovaria tal fato. Note-se que Freud, nas "Lições" (1940b), analisa os atos falhos, reconhecendo as intenções inconscientes como um fato dado pela experiência. 
que só parecia possível, para ele, com uma metapsicologia. Freud sai à busca de outros autores que tivessem se dedicado à elaboração de teorias desse tipo. O comentário que ele faz a Fliess não deixa dúvidas quanto a essa hipótese:

Ortorguei a mim mesmo a tarefa de construir uma ponte entre minha metapsicologia embrionária e a que está contida na literatura especializada e, por conseguinte, mergulhei no estudo de Lipps, que suspeito ter a mente mais lúcida entre os escritores filosóficos da atualidade (Freud \& Fliess, 1986, [26/09/1898], p. 325).

O Projeto é, por vezes, interpretado como a proposta de uma psicologia empírica realista, como se a teoria metapsicológica, apresentada nesse texto, devesse "ser considerada, em todas as suas facetas, uma teoria biológica do controle cognitivo, baseada numa neuropsicologia explícita" (Pribram \& Gill, 1976, p. 7). Nessa perspectiva de leitura, a teoria metapsicológica edificada, posteriormente, por Freud e seus seguidores seria apenas uma cópia dessa primeira metapsicologia do Projeto, uma cópia obscurecida que "privada de suas raízes e definição explícita [com o abandono do Projeto], [via] os mecanismos [psíquicos] ficarem isolados dos desenvolvimentos científicos contemporâneos e, especialmente nas mãos dos psicanalistas pósfreudianos, tornaram-se um emaranhado especulativo de conceitos e sofismas" (p. 4).

No entanto, se consideramos a história e a formação intelectual de Freud, talvez seja mais coerente incluí-lo numa linha de pesquisa de forte herança kantiana, ${ }^{10}$ na qual a ciência é pensada dentro de um ponto de vista heurístico, o que nos levaria a pensar que os modelos propostos por Freud, no Projeto, não visam a realidade empírica de suas construções auxiliares, mas a utilidade destas na resolução de seus problemas clínicos. Trata-se,

10 Creio não ser o caso de fazer, aqui, um desvio argumentativo para confrontar essa interpretação do pensamento de Freud da feita por Gabbi Jr. ( Gabbi Jr. 1994, Cap. 5; 1995, p. 106; ), que defende ser a filosofia de J. S. Mill e não a dada no programa de pesquisa kantiano, a que serve de inspiração a Freud na construção do Projeto tal como defendem Loparic, 1985, 1999a, 2003; Blum, 1998 e Fulgencio, 2001, 2003; bastando, para meu objetivo, indicar, aqui, o kantismo de Freud. 
aqui, para avaliar o que Freud pretende com seus modelos teóricos formulados em termos biológicos no Projeto, mostrar sua proximidade com um aspecto metodológico do programa kantiano para as ciências naturais, no qual o cientista pode utilizar-se de conceitos e modelos especulativos como construções auxiliares que tornam possível observar, organizar e sistematizar os fatos, contribuindo como instrumentos heurísticos para a descoberta das relações efetivas (empiricamente observáveis) entre os fenômenos que deseja explicar, sem que seja esperado que essas especulações, elas mesmas, venham a ter algum referente empírico na realidade fenomênica. Considerase que Freud, quando usa de construções auxiliares ou ficções teóricas, está utilizando esses conceitos tal como Kant defende o uso de ficções heurísticas (1787, B 799) no seu programa de pesquisa para as ciências empíricas de cunho naturalista. Assim, defende-se aqui que a maneira como Freud especula no Projeto está já explicitada, enquanto proceder, em Kant. Um exemplo significativo da proposta de Kant, que remete ao Projeto de Freud, pode ser encontrado numa resposta que ele dá à consulta que Sömmering lhe faz sobre "o órgão da alma" (Kant, 1796/2001). Nesse pequeno comentário, Kant mostra que, no que se refere à procura da sede das sensações, é possível procurar uma solução sobre a sede da alma e as explicações sobre seu funcionamento, recorrendo a modelos especulativos. Ele mesmo indica como isso poderia ser feito pelo fisiologista, supondo que a única matéria possível para abrigar a alma, seria a água que está na cavidade cerebral; mais ainda, essa água deveria ser pensada em termos dinâmicos, referida às forças químicas que estariam na base do seu funcionamento. Kant é explícito ao caracterizar esse modelo proposto como um conjunto de hipóteses muito arbitrárias (Kant, 1796/2001, p. 225), ainda que úteis para a busca de explicações.

Andersson, no seu estudo sobre a pré-história da psicanálise, ressalta dois aspectos significativos para a compreensão do proceder teórico em Freud, relacionados a Kant. Primeiro, ele mostra a importância que a psicologia de Herbart (1776-1841) - para quem o psiquismo é composto por um conjunto de unidades, as representações, que se determinam entre si numa "mecânica das representações" (Vorstellungsmechanik), concebível tal qual um jogo de forças, uma interação dinâmica de idéias - teve para a formação 
e o pensamento de Freud (Andersson, 1997 [1962], p.33 e passim). Convém lembrar que Herbart substitui Kant, após sua morte, na Universidade de Konisberg. Segundo, ressaltando aqui um aspecto que pode esclarecer a concepção teórica que orienta Freud na elaboração do Projeto, Andersson observa que esse tipo de anatomia especulativa, exemplificada acima pela resposta de Kant a Sömmering, era um traço comum a diversas pesquisas sobre o cérebro: "Durante a segunda metade do século XIX, uma abordagem muito comum à compreensão dos fenômenos psíquicos era obtida por uma combinação entre a psicologia associacionista e uma anatomia e fisiologia especulativa do cérebro [também denominada de 'mitologias do cérebro']" (Andersson, 1997, p. 91). Para Andersson, o Projeto é, num de seus aspectos, uma tentativa de Freud de formular a sua mitologia cerebral, ainda que esse tipo de teorização já estivesse relativamente em desuso.

Loparic (2000 [1982]), na sua análise de Kant, ressalta a importância do ponto de vista heurístico no programa de pesquisa kantiano para as ciências da natureza, e avalia que há uma grande proximidade entre Kant e o projeto de Freud. Ele diz, referindo-se ao texto de Freud de 1895:

Em Projeto de uma psicologia para neurólogos (1895), Freud continua essa linha de pesquisa [kantiana]. Na tentativa de modelar o psiquismo, em particular a dinâmica das representações, pelos acontecimentos fisiológicos da matéria cerebral, ele recorreu a conceitos especulativos, tais como "energia nervosa", "soma de excitação", "neurônios" e "vias facilitadas". Dessa forma, Freud produziu um modelo para o órgão da alma, misturando o ponto de vista mecânico com o energético um ponto de vista pós-kantiano, inspirado em W. Ostwald, mas próximo do ponto de vista dinâmico de Kant. (Loparic, 2003, p. 243)

Nessa perspectiva de análise, creio que considerar Freud como um realista, ou seja, como um cientista que tomava suas representações auxiliares - que caracterizam sua metapsicologia, tanto a do Projeto como a que será elaborada mais tarde - como um conjunto de conceitos que teriam um hipotético referente empírico na realidade fenomênica, seja nesse texto, seja em outros momentos de sua obra, além de desconsiderar a sua formação, não é coerente com suas posições epistemológicas e metodológicas, muito mais próximas de Kant e do ponto de vista heurístico na ciência. Isso faz com que 
Freud possa ser considerado como um adido a esse ponto de vista, bem como do uso metodológico de especulações teóricas (no caso a metapsicologia do Projeto) como instrumentos para a descoberta, sem terem, elas mesmas, um valor empírico objetivamente dado. Não é desprovida de significado epistemológico a caracterização que Freud faz da pulsão - conceito fundamental de sua metapsicologia elaborada após o Projeto - como uma idéia abstrata, uma convenção (Freud, 1915a, pp.117-118).

Considero que, para Freud, o modelo metapsicológico do Projeto, organizado a partir dos dados empíricos de sua clínica, não seja um conjunto de hipóteses biológicas que busque um referente empírico objetivo (anatômico) - o que seria uma tarefa muito mais apropriada à neurobiologia do que à psicologia -, mas sim, uma metáfora. Suas representações auxiliares especulativas apresentam-se como um conjunto de conceitos que visam a ajudar a elucidar os problemas clínicos da psicologia e não os da neurobiologia. Isso fica claro no início da segunda parte desse texto, quando Freud enuncia o que fará com sua teoria geral:

A parte I deste projeto continha o que, de certo modo, podia derivar-se a priori das sugestões fundamentais, modelado e corrigido de acordo com diversas experiências factuais. Esta parte II procura atingir [adivinhar; erraten], a partir da análise de processos patológicos, algumas determinações posteriores do sistema fundado sobre essas suposições fundamentais; uma terceira deverá arquitetar [construir, aufbauen], a partir das precedentes, os caracteres do curso psíquico normal. (Freud, $1895 / 1995$, p.59)

Freud diz, ainda, que pretende realizar uma figuração ${ }^{11}$ dos processos psíquicos tanto normais como patológicos, a partir de suas hipóteses que distinguem diversos tipos de neurônios e deslocamentos de quanta de exci-

11 É com esse termo que Freud caracteriza sua tentativa de teorização no início da terceira parte do Projeto: "Tentarei, em primeiro lugar, a apresentação [figuração] psicológica de tais processos [secundários]” (Freud, 1895/1995, p. 371). Mas essa figuração psicológica é constituída por meio de figuras biológicas: "Os processos chamados secundários têm de ser explicados mecanicamente através do efeito que uma massa neuronal de ocupação constante (o eu) exerce sobre outra com ocupações variáveis" (p. 75). 
tação: o Projeto é claramente construído em termos de distribuições energéticas, dentro de uma perspectiva econômico-quantitativa. Ele considerou, naquele momento, que suas suposições - pouco ou quase nada intuitivas, ou seja, não apreensíveis pela observação empírica direta - eram úteis para a elaboração de uma psicologia completa, como uma teoria geral que poderia completar as lacunas até então presentes na explicação dos fenômenos psíquicos. Diz Freud: "Apenas através dessas suposições complicadas e pouco intituitivas foi-me possível, até agora, incluir os fenômenos da consciência na arquitetura da psicologia quantitativa" (Freud, 1895/1995, p. 25). As "suposições complicadas", às quais ele se refere, são a noção de energia nervosa, de quantum de excitação e afeto, os diversos tipos de neurônios, as vias facilitadas para o escoamento dos estímulos e excitações e, mesmo, a suposição, que não é nada evidente, de que o psiquismo pudesse ser pensado tal qual um aparelho dividido em partes que se determinam entre si. Nenhuma dessas construções teóricas tem referente empírico dado pela observação, ao contrário, Freud as toma como frutos do seu fantasiar - ou, como ele diz, na Interpretação dos sonhos, representações desse tipo são ficções teóricas (1900, p. 603) -, cujo objetivo é "reagrupar e explicar os diversos estados psíquicos" (1894, p. 61).

Para Freud, tudo parecia encaixar-se perfeitamente e ele se vê tomado pela alegria de ter encontrado um modelo que pudesse explicar, sem lacunas, os mecanismos que regem a psicologia humana.

Numa noite laboriosa da semana passada, quando eu estava sofrendo daquele grau de dor que propicia as condições ótimas para minhas atividades mentais, as barreiras ergueram-se subitamente, os véus caíram e tudo se tornou transparente - desde os detalhes das neuroses até os determinantes da consciência. Tudo pareceu encaixar-se, as engrenagens se entrosaram e tive a impressão de que a coisa passara realmente a ser uma máquina que logo funcionaria sozinha. Os três sistemas de n[eurônios]; os estados livres e ligados de Qn [quantidade]; os processos primário e secundário; a tendência principal e a tendência dos compromissos do sistema nervoso; as duas regras biológicas da atenção e da defesa; as características de qualidade, realidade e pensamento; e, por fim, os fatores que determinam a consciência como função da percepção - tudo ficou e continua correto até hoje! Naturalmente, mal consigo conter minha alegria. (Freud \& Fliess, 1985 [20/10/1895], p. 147) 
Essa alegria não dura muito. Aproximadamente um mês após essa revelação, ele se mostra totalmente desapontado consigo mesmo e considera ter escrito um tipo de aberração:

Não entendo mais o estado mental em que maquinei a psicologia; não consigo conceber como posso tê-lo infligido a você. Creio que você está sendo polido demais; para mim, parece ter sido uma espécie de aberração. A solução clínica das duas neuroses provavelmente se manterá, depois de algumas modificações. (Freud \& Fliess, 1985, [29/11/1895], p. 153)

Como entender essa mudança de opinião? E por que, ao longo de sua obra, são mantidas as soluções clínicas do Projeto e não, as soluções biológicas? Se as construções auxiliares valem por aquilo que se pode fazer com elas, e não, por sua referência empírica objetiva, então, parece lícito afirmar que Freud considera que uma metapsicologia descrita em termos biológicos é inútil para a prática clínica. Ela nada oferece para a resolução de problemas próprios ao tratamento por meios psíquicos; ${ }^{12}$ ela se apresenta apenas como uma coerente construção teórica, mas que não resulta em nada de prático ou efetivo para o método psicanalítico.

Quando Freud já tinha abandonado o Projeto e estava se dedicando ao seu livro A Interpretação dos sonhos, ele se refere a sua hipótese sobre os sonhos serem a realização de desejos como uma "solução psicológica, e não biológica" (Freud \& Fliess, 1985, [10/03/1898], p. 302), distanciando-se, portanto, da solução biológica e indicando a necessidade de uma solução metapsicológica, que será efetivamente proposta no Cap. VII de A Interpretação dos Sonhos. Essa metapsicologia, apresentada em 1900, será modelada em termos psicológicos (conflito psíquico entre conjunto de representações, atividade psíquica inconsciente, idéias reprimidas, trabalho do sonho, sintomas como realização de desejos, forças psíquicas, sistemas psíquicos etc.), sobre os quais ele sobreporá os aspectos quantitativos, energéticos; ela será, para Freud, uma solução ficcional útil, que resulta em procedimentos

12 Freud, 1890, para essa explicação de tratamento psíquico como sendo um tratamento por meios psíquicos (a sugestão, a palavra, a hipnose). 
de pesquisa (cura) eficientes, pois ajudam o analista a compreender a sua posição e função no tratamento.

O abandono de uma metapsicologia modelada em termos fisiológicos a favor de uma construída em termos psicológicos tem, em Theodor Lipps, um ponto de apoio básico. Esse filósofo é apresentado por Freud - seja em "A Interpretação do Sonhos" (1900, pp. 612-613) e "O Chiste e sua Relação com o Inconsciente" (1905, pp. 161-162), seja em "Esboço de Psicanálise" (1940a, p. 158) e "Algumas Lições Elementares de Psicanálise" (1940b, p. 286) - como uma fonte de suas concepções sobre o psiquismo e o inconsciente. ${ }^{13}$ Para Freud, há em Lipps uma metapsicologia que está, justamente, de acordo com suas posições, não só no que diz respeito à concepção do inconsciente como "a base geral da vida psíquica", ${ }^{14}$ mas também com a necessidade metodológica de manter a psicologia separada da fisiologia. Lipps declara: "Ou se é psicólogo por inteiro, isto é, no sentido amplo da palavra, ou se corre o risco de não o ser de modo algum" (Lipps, 1897/2001, p. 354). Esse autor é da opinião que é um erro confundir psicologia e fisiologia:

As assim chamadas explicações fisiológicas de fenômenos psíquicos são a tradução do conhecimento psicológico, efetivo ou suposto, da linguagem da psicologia para a linguagem da fisiologia do cérebro. Não há, em sentido próprio, uma psicologia fisiológica, ou seja, uma visão do encadeamento e da conformidade a leis dos processos psíquicos, que seria alcançada, em primeiro lugar, no campo da fisiologia. ( p. 355)

Ele chega mesmo a considerar que tal tipo de proposta, que rebate a psicologia numa fisiologia, nada mais é do que uma doença da juventude: "Tudo isso são doenças da juventude que a psicologia tem de vencer" (Lipps, 1897/2001). Para ele, o caminho da psicologia e da psicofisiologia deve ser distinto, para o bom desenvolvimento das duas:

A salvação da psicologia e, com ela, também a salvação da psicofisiologia depende de que a psicologia se erga, cada vez mais, sobre seus próprios pés e, sem se deixar

13 Veja Loparic, 2001, para uma análise da importância de Lipps para Freud.

14 Como diz Lipps, 1897, p. 349; e Freud, 1900, p. 520. 
alterar por coisa alguma, siga seu próprio caminho em direção de suas próprias metas. Na medida em que assim fizer, a psicofisiologia poderá seguir-lhe os passos, mas tão-somente seguir, lenta e cautelosamente, e sempre com pleno conhecimento de assuntos psicológicos. (Lipps, 1897/2001)

O abandono do Projeto como uma metapsicologia descrita em termos fisiológicos ou neurofisiológicos, avaliada por Freud como uma "aberração" (Freud \& Fliess, 1986, [29/11/1895], p. 153), é corroborada pelas posições de Lipps sobre como se deve construir uma psicologia que vai além da psicologia descritiva ou, melhor dizendo, como se deve construir uma metapsicologia propriamente psicológica.

A diferenciação dos tipos de solução propostos para a construção de uma psicologia geral que desse conta dos problemas da psicologia (seja ela normal ou patológica) - com o afastamento da psicofisiologia e com a diferenciação entre as teorias fornecidas pela psicologia (no seu sentido descritivo ou fenomenológico) e as teorias metapsicológicas (modeladas tanto em termos biológicos, como é o caso do Projeto, quanto em termos psicológicos, como se dará após a elaboração do Cap. VII de A Interpretação dos sonhos) - mostra uma opção epistemológica e metodológica de Freud.

Pode-se dizer que, enquanto a compreensão biológica dos mecanismos psíquicos ou mesmo a compreensão que uma metapsicologia descrita em termos biológicos pode ajudar a formular não resultam em ações específicas para o tratamento psicológico, a solução psicológica e a metapsicológica, modeladas em termos psíquicos dinâmicos, enriquecem e aumentam a eficiência do tratamento psíquico. Ou seja, é o critério heurístico e não o da validade objetiva, empírica, o que decide pelo abandono de uma metapsicologia descrita em termos biológicos por uma descrita em termos psicológicos. Esse critério heurístico é retomado por Freud em 1938, quando está escrevendo o que ele sabia ser a sua última síntese sobre a doutrina psicanalítica, dizendo que seria infrutífero (Freud, 1940b, p. 294) conceber o psiquismo reduzido ao consciente, justificando a noção de inconsciente. Logo, pode-se também afirmar que é igualmente infrutífero conceber o inconsciente como uma realidade biológica, ou ainda, descrito metaforicamente por termos biológicos. Para Freud, tanto a metapsicologia psicológica quanto a 
metapsicologia biológica são ficções heurísticas, elas não valem por corresponderem mais ou menos aos fatos, mas porque são mais ou menos úteis para organização, sistematização e busca dos fatos e suas relações. ${ }^{15}$ Para Freud, as representações ou conceitualizações do tipo metapsicológico são, dirá em 1925, uma "superestrutura especulativa [spekulativer Überbau] da psicanálise, em que cada parte pode ser sacrificada ou trocada sem dano nem remorso, a partir do momento em que uma insuficiência é constatada" (1925, p. 32).

Fulgêncio, L. (2004). The Project as a Biological Metaphor of Psychic Processes. Psicologia USP, 15(3), 117-135.

\begin{abstract}
This article intends to demonstrate that the Project of a Psychology, written by Freud in 1895, is a metaphor. It corresponds to the first attempt made by Freud to produce a general theory of the psyche, in which we encounter a metapsychology formulated in biological terms. It is defended that this metapsychology is not proposed as a neuropsychology, but as a set of auxiliary constructions, speculative in nature, whose value is only heuristic, applicable to problems of psychic nature related to the method of treatment that Freud was developing.
\end{abstract}

Index terms: Metapsychology. Metaphor. Neuropsychology.

Fulgêncio, L. (2004). L'Esquisse comme métaphore biologique des processus psychiques. Psicologia USP, 15(3), 117-135.

Résumé: Cet article se propose de montrer que l'Esquisse d'une psychologie Scientifique, écrit par Freud in 1895, est une métaphore. Il correspond à la première tentative de Freud de produire une théorie générale du psychisme. On peut dire que cet essai est une métapsychologie

15 Veja uma análise da natureza e função da teoria metapsicológica em Freud, em Fulgencio, 2003. 


\section{O Projeto como uma Metáfora Biológica dos Processos Psíquicos}

formulée en termes biologiques. L'auteur soutient que cette métapsychologie n'est pas proposée comme une neuropsychologie, mais qu'elle est surtout un ensemble de constructions auxiliaires, spéculatives, qui n'ont qu'une valeur heuristique. Cette métapsychologie, construite de cette manière, est appliquée aux problèmes de nature psychique en rapport avec la méthode de traitement que Freud était alors en train de développer.

Mots clés: Métapsychologie. Métaphore. Neuropsychologie.

\section{Referências}

Andersson, O. (1997). Freud avant Freud. La préhistoire de la psychanalyse (18861896). Condé-sur-Noireau, France: Synthélo Groupe.

Assoun, P.-L. (1981). Introduction à l'épistemologie freudienne. Paris: PUF.

Assoun, P.-L. (1995). Freud, la philosophie et les philosophes. Paris: PUF. (Trabalho original publicado em 1976).

Blum, V. L. (1998). O estatuto das entidades à luz da teoria kantiana das idéias. Campinas, SP: Centro de Lógica, Epistemologia e História da Ciência - Unicamp.

Ellenberger, H. F. (1994). Histoire de la découverte de l'inconscient. Mesnil-surl'Estrée: Fayard. (Trabalho original publicado em 1970)

Etcheverry, (1976). In S. Freud, Obras completas (Vol. 1, p. 339). Buenos Aires: Amorrortu.

Freud, S. (1884). La estrutura de los elementos del sistema nervioso. In S. Freud, Obras Completas (Vol. 1). Buenos Aires: Amorrortu.

Freud, S. (1890 [1905]). Psychal (or mental) treatment. In S. Freud, Standard edition of the complete psychological works of Sigmund Freud(Vol. 7, James Strachey, trad.). London: The Hogarth Press.

Freud, S. (1894). The defense neuro-psychoses. In S. Freud, Standard edition of the complete psychological works of Sigmund Freud (Vol. 3, James Strachey, trad.). London: The Hogarth Press.

Freud, S. (1897). Abstracts of the scientific writings of Dr. Sigm. Freud 1877-1897. In S. Freud, Standard edition of the complete psychological works of Sigmund Freud (Vol. 3, James Strachey, trad.). London: The Hogarth Press. 
Freud, S. (1900). The interpretation of dreams. In S. Freud, Standard edition of the complete psychological works of Sigmund Freud (Vol. 4-5, James Strachey, trad.). London: The Hogarth Press.

Freud, S. (1905). Wit and ist relation to the unconscious. In S. Freud, Standard edition of the complete psychological works of Sigmund Freud (Vol. 8, James Strachey, trad.). London: The Hogarth Press.

Freud, S. (1915a). Instincts and their vicissitudes. In S. Freud, Standard edition of the complete psychological works of Sigmund Freud (Vol. 14, James Strachey, trad.). London: The Hogarth Press.

Freud, S. (1915b). The unconscious. In S. Freud, Standard edition of the complete psychological works of Sigmund Freud (Vol. 14, James Strachey, trad.). London: The Hogarth Press.

Freud, S. (1925). An autobiographical study. In S. Freud, Standard edition of the complete psychological works of Sigmund Freud (Vol. 20, James Strachey, trad.). London: The Hogarth Press.

Freud, S. (1940a). An outline of psychoanalysis. In S. Freud, Standard edition of the complete psychological works of Sigmund Freud (Vol. 23, James Strachey, trad.). London: The Hogarth Press.

Freud, S. (1940b). Some elementary lessons in psycho-analysis. In S. Freud, Standard edition of the complete psychological works of Sigmund Freud (Vol. 23, James Strachey, trad.). London: The Hogarth Press.

Freud, S. (1983). Contribuitions à la conception des aphasies. Paris: PUF. (Trabalho original publicado em 1891)

Freud, S. (1995). Projeto de uma psicologia. Rio de Janeiro: Imago. (Trabalho original publicado em 1895)

Freud, S., \& Fliess, W. (1986). A correspondência completa de Sigmund Freud para Wilhelm Fliess - 1887-1904. Rio de Janeiro: Imago.

Freud, S. \& Jung, G. (1992). Correspondance 1906-1914. Paris: Gallimard.

Fulgencio, L. (2001). Comentários críticos das referências textuais de Freud a Kant. Psicologia USP, 12(1), 49-88.

Fulgencio, L. (2003). As especulações metapsicológicas de Freud. Natureza humana, $5(1), 127-164$.

Gabbi Jr, O. F. (1994). Freud: racionalidade, sentido e referência. Campinas, SP: Unicamp/CLE.

Gabbi Jr, O. F. (1995). Notas críticas sobre Entwurf Einer Psychologie. In S. Freud, Projeto de uma psicologia. Rio de Janeiro: Imago. 
Jones, E. (1992). La vie et l'oeuvre de Sigmund Freud (Vol. 1). Paris: PUF. (Trabalho original publicado em 1953)

Kant, I. (1997). Crítica da razão pura. Lisboa: Fundação Calouste Gulbenkian. (Trabalho original publicado em 1787)

Kant, I. (2001). Observações referentes a Sobre o órgão da alma. Natureza Humana, 5(1), 223-229. (Trabalho original publicado em 1796)

Knoblock, F. (Org.). (1991). O inconsciente: várias leituras. São Paulo: Escuta.

Lipps, T. (2001). O conceito de inconsciente na psicologia. Natureza Humana, 3(1), 335-356. (Trabalho original publicado em 1897)

Loparic, Z. (1985). Resistências à psicanálise. Cadernos de História e Filosofia da Ciência, (8), 29-49.

Loparic, Z. (1991). Um olhar epistemológico sobre o inconsciente freudiano. In F. Knoblock (Org.), O inconsciente: várias leituras (pp. 45-58). São Paulo: Escuta.

Loparic, Z. (1999a). O conceito de Trieb na filosofia e na psicanálise. In J. A. T. Machado (Org.), Filosofia e psicanálise: um diálogo. Porto Alegre: EDIPCRS

Loparic, Z. (1999b). É dizível o inconsciente. Natureza Humana, 1(2), 323-385.

Loparic, Z. (2000 [1982]). A semântica transcendental de Kant. Campinas, CLE.

Loparic, Z. (2001). Theodor Lipps: uma fonte esquecida do paradigma freudiano. Natureza Humana, 3(1), 315-331.

Loparic, Z. (2003). De Kant a Freud: um roteiro. Natureza Humana, 5(1), 231-245.

Mach, E. (1922). La conaissance et l'erreur. Paris: Flammarionn. (Trabalho original publicado em 1905)

Machado, J. A. T. (Org.). (1999). Filosofia e psicanálise: um diálogo. Porto Alegre: EDIPCRS.

Pribram, K., \& Gill, M. (1976). O projeto de Freud: um exame crítico. São Paulo: Cultrix. 